\title{
On the Development of Agricultural Professional Managers
}

\section{Li Wenwu, Zheng Yan}

School of Business Administration, Inner Mongolia University of Finance and Economics, Hohhot, China

Email address:

lww116@126.com (Li Wenwu)

\section{To cite this article:}

Li Wenwu, Zheng Yan. On the Development of Agricultural Professional Managers. Journal of Human Resource Management. Vol. 8, No. 1, 2020, pp. 16-20. doi: 10.11648/j.jhrm.201200801.13

Received: February 23, 2019; Accepted: December 17, 2019; Published: January 17, 2020

\begin{abstract}
As an important team of rural talents, agricultural professional managers love agriculture, understand technology, manage well and manage well. They have higher comprehensive quality and professional accomplishment. However, the cultivation of agricultural professional managers is heavy task and great significance. All localities need to base their efforts on the overall situation and long-term perspective, and effectively integrate the cultivation of new-type professional farmers into the overall arrangement of agricultural rural economic work. As a key work in the current and future periods, the cultivation should be systematically planned and carried out in an orderly way. In particular, top-level design should be carried out as soon as possible to actively explore effective measures and methods to ensure good service. The agricultural professional managers are an important force in the strategy of rural revitalization. The development of agricultural professional managers is a systematic project. The development of agricultural professional managers involves entry mechanism, training mechanism, incentive and restraint mechanism, examination and withdrawal mechanism, service mechanism, etc.
\end{abstract}

Keywords: Managers, Agriculture, Countryside

\section{Introduction}

Agricultural professional managers are produced along with the development of modern agriculture to a certain stage They refer to agricultural skilled personnel who operate and control the resources and capital needed for agricultural production and management, and obtain commissions or dividends from them while seeking the greatest economic benefits for farmers' cooperatives, agricultural enterprises or agricultural enterprise owners [1]. As an important team of rural talents, agricultural professional managers love agriculture, understand technology, manage well. They have higher comprehensive quality and professional accomplishment. However, the development of agricultural professional managers started relatively late, with heavy development tasks and many contents. With the implementation of the rural revitalization strategy, the demand for agricultural professional managers continues to increase. This requires relevant departments to effectively integrate the development of agricultural professional managers into the overall deployment of agricultural rural economic work based on the overall situation and long-term perspective. All relevant departments should plan systematically and advance in an orderly way on the whole, and take the development of agricultural professional managers as a systematic project to carry out scientific and effective development [2].

\section{Entry Mechanism}

Agricultural professional managers must receive a unified qualification certificate after strict training before entering the hiring market. The application of agricultural professional managers generally needs to adopt a combination of voluntary registration and local government recommendation [3]. The main sources of personnel are experienced farming experts, sales experts, technical experts, outstanding talents returning home to start their own businesses, etc. Agricultural professional managers can be divided into junior, intermediate and senior agricultural professional managers based on the registration of talents. The length of years that different levels of agricultural professional managers are engaged in agricultural production and management should be scientifically set. For example, primary agricultural professional managers should be engaged in agricultural production and management for at least two years, and the operating years of other levels of agricultural professional 
managers should also be correspondingly limited [4]. Production should reach a certain scale, for example, the output value of the entity established by the senior agricultural professional manager's leading office or mainly responsible for production and operation should reach more than 5 million yuan, and its reputation is good, etc.

The establishment of an agricultural professional manager qualification certification system will divide the qualification level into primary, intermediate and senior levels according to their management ability, working years and performance [5]. The government department will issue qualification certificates to those who pass the qualification. For agricultural professional managers who meet the standards, a unified "certificate of agricultural professional managers" will be issued.

\section{Training Mechanism}

Improve the management of teachers. Set up an expert and talent workstation to check and assess the work of experts in the implementation of projects, topics, base construction, experimental demonstration, achievement promotion, teaching and training in agricultural research institutes [6]. The performance appraisal system shall be implemented for the assessment of teachers; the back deduction system shall be implemented for the experts who fail to implement the project according to the schedule and the contents and standards of the project application form, and 5-10 points shall be deducted each time as the case may be; the bonus system shall be implemented for the experts who make special contributions to modern agriculture, and the bonus shall not exceed 20 points; the assessment results shall be included in the expert evaluation results at the end of the year. The teaching staff should reached specialization and scale, which makes the rural professional managers to progress and develop in a virtuous circle. At the same time, it also forms the industrialization development of the teachers' team and the systematization and standardization of teachers' assessment.

The training targets are mainly college graduates, with a certain degree of education and agricultural production management skills, sales experts returning home to start their own businesses, large agricultural producers and management who are familiar with agricultural production and management [7] Through voluntary registration by individuals, the competent agricultural administrative department at the county level will carry out screening, register personnel who meet the basic conditions and are willing to engage in agricultural production and management, and incorporate them into the training plan.

Training institutions: local colleges and other departments jointly set up an agricultural professional managers' college to train the trainees. For example, Chengdu institute of agricultural professional managers is listed in Chengdu institute of agricultural science and technology [8]. It integrates relevant agricultural colleges, vocational colleges, technical vocational colleges, forestry colleges, radio and TV universities, etc. These colleges and universities jointly participate in the cultivation of agricultural professional managers, give full play to the resource advantages of all colleges and universities, integrate resources, and provide a better development platform for the training of agricultural professional managers [8].

The training content, combined with the actual situation of agricultural professional managers, its training courses mainly include agricultural science and technology management, agricultural product marketing, agricultural product quality and safety, agricultural informationization, rural finance, agricultural laws and regulations, rural e-commerce and so on. At the same time, it mainly focuses on the theoretical issues of social and economic development, social hot issues and policies to benefit farmers. According to their own problems in quality and ability, it carries out order-based training courses to improve their specific quality and ability.

Establish teacher training system. Establish a system of direct contact between agricultural technology experts and rural agricultural technicians, and give full play to the important role of scientific and technological personnel in technical guidance and follow-up services.. The training system gives full play to the theoretical and practical knowledge of experts, focusing on providing farmers with single training and independent projects as well as professional agricultural technical services. Experts, agronomists teach the agricultural production management of the latest production technology, carry out scientific and technological demonstrations, and promote agricultural technology [9].

Training model. Establish a four-in-one training model for government, universities, trade associations and enterprises. As the leader in the training of agricultural professional managers, the government can establish a system of regulations, establish a guiding and incentive mechanism in policies, give financial support to training institutions for agricultural professional managers, establish training centers across enterprises, regions and trades, give full play to the leading and guiding role of the government in training, and integrate the advantageous resources of different universities. As the main body in training, colleges and universities should focus on improving the professional competence of agricultural professional managers, refer to industry standards and enterprise standards, combine national professional qualification certification standards, integrate the advantages of different disciplines and specialties in colleges and universities, and build "aircraft carriers" for training. The trade association is the main maker of professional qualification standards, the spreader of market information, and the carrier of the whole training process. The trade association should formulate standards for the supervision and quality assessment of rural professional managers [10]. It should gradually establish and perfect the trade association of agricultural professional managers, and perfect the standards for agricultural professional managers and their relevant entry, evaluation, promotion and exit mechanisms. Agricultural enterprises should participate in the training to ensure that the trained agricultural professional managers are truly suitable 
for the needs of agricultural enterprises, so that the research on problems in the development of agricultural enterprises corresponds to the training needs of agricultural professional managers, so that the training is purposeful, oriented and practical. Agricultural enterprises can provide training places and bases for professional managers, and at the same time analyze the training needs of agricultural professional managers. Combining with the local actual situation, the training content is directional and practical, so that the training results have an immediate effect.

Training methods. Training methods should be diversified and flexible training modes should be adopted according to the training content. The training and education of new rural professional managers should not only emphasize systematic, scientificalness and pertinence, but also emphasize flexibility and practicality [11]. It is not only convenient for professional agricultural managers to learn theoretical knowledge, but also convenient for professional agricultural managers to learn practical agricultural knowledge. According to the characteristics of the course, short-term training and centralized training are combined in teaching methods. Theoretical lectures, on-site meetings, observation and exchange meetings and other forms are used, while some skills training should adopt the mode of practical operation.

Establish tutor cultivation system. Establish the cultivation system of direct contact between agricultural technology experts and rural agricultural technicians, and give full play to the important role of two-level scientific and technological personnel in technical guidance and tracking services. The cultivation system gives full play to experts' theoretical and practical knowledge, and focuses on providing farmers with single training plan and specialized agricultural technology service guidance. Experts, agricultural technologists and agricultural professional managers should not only impart the latest production technology to professional farmers, but also carry out scientific and technological demonstration, and promote and popularize agricultural technology [12]. At the same time, we should innovate the information of teachers' database, establish the circulation platform of teachers, and achieve the circulation between professional farmers and the latest scientific and technological talents in agriculture.

Combine theory with practice. The practical teaching content mainly includes cultivation professional technology and production skills, agricultural operation and management ability, and the theoretical training mainly includes management theory, management method, etc. Reasonable curriculum and content setting not only ensure the agricultural production of agricultural professional managers, but also improve their comprehensive quality. The courses are designed to avoid the shortage of labor force when farmers are busy in the countryside. They make efficient use of their time when they are idle in the countryside. The contents of the courses not only include the original theoretical courses, but also include the practical training practice in the content setting. The combination of theory and practice improves and enriches farmers' agricultural technology and vision.

\section{Incentive and Restraint Mechanism}

Increase material incentives, increase the proportion of performance salary while increasing fixed salary, and increase the proportion of performance salary according to performance contribution. First is the need to link the business results of enterprises with the personal income of rural professional managers. This kind of behavior has short-term incentive effect [13]. This kind of mechanism is mainly to directly link the personal income of rural professional managers with their work performance, which can strengthen the work enthusiasm and management effect of rural managers. The annual salary system and other compensation systems with long-term incentives can be set up. Through the design of compensation plans for agricultural professional managers, such as stock options, the short-term interests of professional managers can be reconciled with the long-term interests of enterprises, thus reducing the conflicts between the interests brought about by the short-term behaviors of professional managers, increasing the opportunity cost of the short-term behaviors of professional managers, and reducing the motivation of the short-term behaviors of professional managers. At the same time, pay attention to spiritual motivation, and outstanding rural professional managers can be awarded the corresponding model worker title or "51 medal" to enhance social status and meet their spiritual needs.

When a professional manager enters an enterprise for employment, he / she signs an employment contract protected by law with the enterprise to clearly define the duties and rights of the professional manager. In particular, when the professional manager leaves the enterprise, he / she strictly limits the responsibilities that should be attached to the business secrets and technical patents of the enterprise, thus forming an effective restriction on the agricultural professional manager [14]. To improve the supervision the relevant government departments and trade associations should restrict the behavior of agricultural professional managers in their management. Continuously strengthening the management of the rural professional manager market will correspondingly raise the evaluation standard of the rural manager's behavior, and it will also be easier to find the opportunist behavior of the rural professional manager in the actual management. If the manager is found to have such behavior, they will meet the fate of being eliminated.

\section{Assessment and Withdrawal Mechanism}

Agricultural professional managers have to undergo double assessment by the employment council and the government. Enterprises should assess the operating performance of agricultural professional managers according to the contents of the contracts signed in advance. The government establishes an evaluation mechanism for agricultural professional managers, which evaluates them once every year or two, evaluates the performance of agricultural professional managers scientifically according to performance standards, 
and raises or lowers their professional grades, etc. The local government also gives corresponding recognition and rewards to the outstanding agricultural professional managers who have been evaluated. For agricultural professional managers who fail to pass the examination, the withdrawal mechanism shall be implemented. If agricultural professional managers have problems in agricultural product quality and safety, violation of laws and regulations and honesty, they will implement a one-vote veto system, disqualify agricultural professional managers, and withdraw from the government's talent information management resource.

\section{Service Mechanism}

Using the results of the registration and certification of rural land ownership, we will continue to do a good job in the reform of separation of three rightsand continuously improve the supporting policies and operating mechanisms of agricultural socialized services. We will integrate the agricultural supply chain system of production, processing, circulation and service of agricultural products, and provide convenience for agricultural professional managers to organize the development of modern agriculture with the integration of planting, breeding, production, supply and marketing, and domestic and foreign trade.

Establish a database of agricultural professional managers' talent resources, and timely disclose dynamic information on the specialty, performance, and credit of agricultural professional managers, so as to promote their exchange and employment within provinces (regions). Set up an agricultural professional manager service center to provide policy consultation, relevant formalities and other services for agricultural professional managers. Encourage the establishment and development of professional managers' associations in agriculture, and promote the exchange and study of professional managers in production and management, construction of agricultural product parks, product design and marketing, etc.

Agricultural service companies set up agricultural service supermarkets to provide professional managers with agricultural technology consulting, labor services, agricultural machinery services, agricultural materials distribution, pest control, food storage and other services. The innovative service methods meet the professional managers for agriculture. Different needs of all aspects of scale and industrial specialization. The cultivation of new professional farmers should break through the limitations of producing primary agricultural products, realizing the production and supply of goods, the marketization of agriculture, industry and commerce, and the further extension of the industrial chain [15].

Professional managers who have obtained certificates can enjoy the agricultural production loan policy, and the funds can only be used in agricultural production and management and related fields. At the same time, he/she can enjoy the exemption guarantee fee, there is a $50 \%$ interest subsidy, he/she will have a $20 \%$ reduction and exemption policy for participating in agricultural insurance. This not only reduces the production costs of rural managers, the insurance cost subsidies reduce the worries of the operators, but also greatly enhance the manager's production enthusiasm.

Establish a development mechanism for agricultural professional managers that combines self-cultivation with the introduction of talents, and combines theoretical training, skill training, practical training, etc. to create a good ecological environment for the growth of agricultural professional managers.

Agricultural professional managers are an important part of rural revitalization. Only by cultivating more agricultural professional managers can we make rural construction better, more civilized and more modern and realize a well-to-do society in rural areas as soon as possible.

\section{Conclusion}

The emergence of professional managers in rural areas is the inevitable outcome of urbanization, so that farmers with ideals, pursuits and agricultural skills can join in this rank, promote large-scale farming methods, while giving full play to their strengths and achieving their own income growth, can lead more farmers to the road of prosperity.

\section{References}

[1] Zhu chunxiu: Thoroughly implement the spirit of the party's 19th national congress and effectively strengthen the service guarantee for cultivating agricultural professional managers [j], Sichuan agriculture and agricultural machinery, 2017, (6): 1.

[2] Xie ruiwu. Cultivating agricultural professional managers to develop new agriculture [j]. Rural work newsletter, 2014, (19): 43-44.

[3] Yan Rong and Yang jie: Cultivation practice of agricultural professional managers based on agricultural supply-side reform [j]. Grain science and technology and economy, 2017 (5): $12-15$.

[4] Yang jianhong etc: Research on professional standards of agricultural professional managers under the new agricultural management system [j], Heilongjiang animal husbandry and veterinary science, 2016 (1): 196-198.

[5] Xia Fang, etc. Study on the restrictive factors and countermeasures for tobacco farmers' cooperatives to introduce professional managers in agriculture [j]. Chinese journal of tobacco, 2018, (1): 106-110.

[6] HanWenlong and Xie lu: Formation mechanism and wage contract of agricultural professional manager market [j]. Financial science, 2017, (6): 58-66.

[7] Zhao ru. Cultivation of agricultural professional managers competence under the strategy of rural revitalization [j], The rural economic, 2018, (7): 16-21.

[8] Ning manxiu, etc. Rural revitalization: International experience and China practice [j], China's rural economy, 2018, (12): 130-139.

[9] Chen juan Ma guosheng. Study on the integration of produce of production and education of new professional farmers for rural revitalization [j], 2018, 46 (34): 232-234. 
[10] Zhong guangrong. The predicament and outlet of cultivating new peofessional farmers under the strategy of rural revitalization [j], Modern agricultural technoiogy, 2018, (21): 287-288.

[11] Li dongbo etc. Current situation and suggestion of rural talent team construction [j], Crop research, 2018, 32 (7), 80-82.

[12] $\mathrm{Wu}$ zhiqian, etc. Exploration on cultivation path of professional managers in modern agriculture [j], Modern agricultural technology, 2018, (24): 281-283.
[13] Papinaho oili. Etc. Integrative review of studies about nurses who have been disciplined by their professional regulatory bodies [j], Journal of nursing management, 2019, (9). 11-15.

[14] Xiong kaixia, Feng yongxiang. Development of vane professional manager system to business partnership system [j], Technology and Economic Guide, 2019, (27): 178-180.

[15] Li yun, Liu jie. Equity incentive for professional managers of family enterprises in China [j], The southern financial, 2019, (9): 63-70. 